\title{
UN BREVE ESTUDIO SOBRE LA CUESTIÓN DE LA REDUCCIÓN DE LA MAYORIDAD PENAL EN EL SISTEMA JURÍDICO BRASILEÑO
}

\author{
A bRIEF STUdy ON THE MATTER OF tHE REDUCTION OF THE AGE OF CRIMINAL \\ RESPONSIBILITY IN THE BRAZILIAN LEGAL SYSTEM
}

Rocco Antonio Rangel Rosso Nelson*

Instituto Federal de Rio Grande do Norte - IFRN / Brasil

\section{Resumen}

En consecuencia del agravamiento de la violencia, en el seno de la sociedad brasileña, la cual alcanza todos los estratos sociales, desde la periferia hasta la alta clase, donde la impotencia de los órganos y entidades estatales de seguridad se presenta con claridad. El estado de inseguridad se amplía como consecuencia de un periodismo sensacionalista, de momento, que esparce terror e infla los ánimos sociales. En ese diapasón, las entidades gubernamentales recurren al Derecho Penal, como solución milagrosa, donde se busca la criminalización de más conductas y el endurecimiento de las penas. En este escenario de caos institucional frente a la violencia, que de hecho hay, que tramita la Propuesta de Enmienda a la Constitución N. ${ }^{\circ} 171$ de 1993, que tiene el fin de reducir la mayoría de edad penal, de 18 años a 16 años, como uno de los frentes de edad combate de la expansión de la criminalidad. La investigación, haciendo uso de una metodología de análisis cualitativo y los métodos de enfoque hipotético-

Master en Derecho Constitucional por la Universidad Federal de Rio Grande do Norte (UFRN). Con especialización en Derecho y Ciudadanía por la Escuela Técnica Superior del Ministerio Público de Rio Grande do Norte. Tiene una especialización en Derecho Penal y Criminología por la Universidad Potiguar. Fue profesor de derecho y otros cursos de pregrado y posgrado en el Centro Universitario FACEX. Líder del Grupo de Estudio e Investigación sobre Extensión y Responsabilidad Social, vinculado a la línea de investigación «Democracia, Ciudadanía y Derechos Fundamentales» del Instituto Federal de Rio Grande do NorteIFRN, campus Natal-Central. Catedrático de Derecho en el Instituto Federal de Río Grande del Norte - IFRN, campus João Câmara. Autor de los libros Curso de Derecho Penal - Teoría general del delito vol. I y Curso de Derecho Penal - Teoría general de la pena vol. II. 
deductivos de carácter descriptivo y analítico, tiene por línea de fondo analizar el tema de la reducción de la edad penal y su (in)adecuación a los mismos vectores axiológicos sociales esculpidos en la Constitución Federal.

Palabras clave: Ofensa a la esencia de la Constitución; Propuesta de Enmienda a la Constitución N. ${ }^{\circ}$ 171/93; imputación penal, reducción de la mayoría de edad penal.

\section{Abstract}

As a result of the worsening violence, within Brazilian society, which reaches all social strata, from the periphery to the upper class, in which the impotence of state security organs and entities is palmar. The insecurity state expands as a result of a momentaneously sensationalist journalism, that spreads horror and inflates social spirits. In that fingerboard, government entities draw on to Criminal Law, as a miraculous solution, in which criminalization of conducts and hardening of penalties are sought. In this scenario of institutional chaos opposite violence, it is dealt with in the Proposal for Amendment to the Constitution N. ${ }^{\circ} 171$ of 1993 , with aims to reduce the age of criminal responsibility, from 18 years to 16 years as one of the age combat attempts against the spread of crime. The following study, using a qualitative analysis methodology, using the hypothetical-deductive approach methods of a descriptive and analytical nature, has the purpose to analyze the issue of the reduction of the criminal age and its (in) adaptation to the same social axiological vectors sculpted, in the Federal Constitution

Keywords: Offense to the essence of the constitution; Propuesta de Enmienda a la Constitución N. ${ }^{\circ} 171 / 93$; Criminal imputation; Reduction of the age of criminal responsibility

\section{"Quien es capaz de hacer creer en absurdos es capaz de hacer que usted cometa atrocidades».}

Voltaire 


\title{
I. DE LAS CONSIDERACIONES INICIALES
}

\author{
El legislador estableció en el artículo 27 del Código Penal una presunción \\ legal absoluta de que los menores de 18 ańos no poseen capacidad para el \\ entendimiento de la conducta criminal, quedando los mismos sujetos a \\ legislación especial ${ }^{1}$.
}

La opción por la edad de 18 años es fruto de la política criminal, quebusca no contaminar al joven infractor con los efectos deletéreos de la convivencia penitenciaria, como bien se describe en el ítem 23, de la exposición de motivos del Código Penal, referente a la reforma de 1984:

Manteve o Projeto a inimputabilidade penal ao menor de 18 (dezoito) anos. Trata-se de opção apoiada em critérios de Política Criminal. Os que preconizam a redução do limite, sob a justificativa da criminalidade crescente, que a cada dia recruta maior número de menores, náo consideram a circunstância de que o menor, ser ainda incompleto, e naturalmente anti-social na medida em que não é socializado ou instruído. O reajustamento do processo de formação do caráter deve ser cometido à educaçáo, náo à pena criminal. De resto, com a legislaçáo de menores recentemente editada, dispóe o Estado dos instrumentos necessários ao afastamento do jovem delinqüente, menor de 18 (dezoito) anos, do convívio social, sem sua necessária submissão ao tratamento do delinqüente adulto, expondo-o à contaminação carcerária.

El menor de 18 ańos que practica conducta en los términos de las prescripciones criminales o de las contravenciones penales realiza el llamado acto infractor, como dispone el artículo 103 de la Ley N. ${ }^{\circ} 8.069 / 90$ (Estatuto del Niño y del Adolescente) $)^{2}$.

1 Sobre um breve relato histórico da idade penal, aferir Maximiliano e Maximilianus Führer: «É antiga a relação da idade com o grau de responsabilidade penal. Em Roma (Lei das XII Tábuas) os menores eram classificados em púberes e impúberes, sendo que os últimos estavam sujeitos a medidas administrativas (castigatio). Em alguns momentos a responsabilidade criminal foi fixada aos sete anos de vida. Durante O primitivo Direito Bárbaro pouco importava a idade do autor do fato, já que o objetivo principal do Direito Penal era a reparação de danos. A idade somente começou a ter relevância para os alemães quando passaram a considerar também os aspectos subjetivos do delito. No Direito Canônico os impúberes, em princípio, eram inimputáveis, mas isto dependia de o juiz verificar no caso concreto o discernimento do réu. As Ordenaçōes Filipinas adotaram um sistema semelhante. A pena era aplicada integralmente aos maiores de 20 anos, ficando ao arbítrio do julgador a reduçáo do castigo no caso de agente maior de 17 e menor de 20 anos. Nesta hipótese, a sanção poderia ser integral se o menor demonstrasse suficiente malicia. As legislaçôes atuais fixam o limite da responsabilidade penal de forma não harmônica, variando a idade mínima, conforme o país, de 12 a 20 anos de idade». (Führer, 2010, pp. 58 y 59).

2 ECA. Artículo 103. Considera-se ato infracional a conduta descrita como crime ou contravenção penal. 
En la práctica del acto infractor se podrán aplicar las siguientes medidas socioeducativas, según el artículo 112 el Estatuto da Crinça e do Adelescente (ECA):

I - advertência;

II - obrigação de reparar o dano;

III - prestação de serviços à comunidade;

IV - liberdade assistida;

$\mathrm{V}$ - inserção em regime de semi-liberdade;

VI - internação em estabelecimento educacional;

VII - qualquer uma das previstas no artículo 101, I a VI. ${ }^{3}$

Se llama la atención al inciso VI, reciente es la internación en establecimiento educativo, la cual perdurará por el plazo máximo 3 años, con reevaluación del comportamiento cada 6 meses.

En el intersticio entre la publicación del Código Penal de 1940 y el Estatuto del Nińo y del Adolescente de 1990, se suceden diversas Constituciones, habiendo, con la Constitución ciudadana de 1988, el proceso de constitucionalización de los derechos del niño y del adolescente, el criterio de la minoridad penal, inferior a 18 años de edad (ya adoptado por el Código Penal), como límite a la imputabilidad penal y, consecuentemente, de la apreciación de la culpabilidad delictiva, en los términos del artículo 228 de la Constitución:

Artículo 228. São penalmente inimputáveis os menores de dezoito anos, sujeitos às normas da legislação especial.

Sin embargo, con los medios tecnológicos de acceso a la información hubo, sin duda un proceso de maduración y concientización del joven, en un nivel superior del adolescente de la década de 1940.

3 ECA. Artículo 101. Verificada qualquer das hipóteses previstas no artículo 98, a autoridade competente poderá determinar, dentre outras, as seguintes medidas:

I - encaminhamento aos pais ou responsável, mediante termo de responsabilidade;

II - orientação, apoio e acompanhamento temporários;

III - matrícula e freqüência obrigatórias em estabelecimento oficial de ensino fundamental;

IV - inclusão em programa comunitário ou oficial de auxílio à família, à criança e ao adolescente; $\mathrm{V}$ - requisição de tratamento médico, psicológico ou psiquiátrico, em regime hospitalar ou ambulatorial;

VI - inclusão em programa oficial ou comunitário de auxílio, orientação e tratamento a alcoólatras e toxicômanos 
Se agrega a ello un creciente índice de violencia, el cual sólo ha aumentado, década tras década, advirtiéndose un aumento de los actos infractores perpetrados por niños y adolescentes, no sólo en cantidad, sino también en gravedad.

Con el periodismo policial que explora de forma sensacionalista ${ }^{4}$, y que, por lo que respecta a las mejores razones de la norma constitucional y legal, se tiene un estado de inseguridad de terror extremadamente potenciado.

En razón a ello es que se recurre a las nuevas proposiciones, en materia penal, de carácter demagógicas, donde se imputa al Derecho penal la culpa por la blandura de sus penas, propugnando por un Estado de excepción, donde la pena sería aplicada con el rigor máximo de formar intimidar al «bandidaje».

En un plexo de variables determinantes para la conducta criminal y para los actos infractores, se vende la idea de que la solución de que debe haber más conductas criminalizadas y de penas más duras.

Es en este execrable contexto de un claro Derecho Penal simbólico que tiene en trámite, de forma más avanzada, la Propuesta de Enmienda a la Constitución N. ${ }^{\circ} 171 / 92$, que altera la redacción del artículo de la Constitución Federal, reduciendo la edad penal a 16 ańos, ventilándose, así la idea de que la aplicación de la sanción penal, en lugar de la sanción prevista por el Estatuto del Niño y del Adolescente, contendría el alza de las estadísticas referente a la violencia perpetrada por adolescentes de entre 16 y 18 años.

Es innecesario resaltar el debate hercúleo que la temática de la reducción de la edad penal genera en los ámbitos político, académico, jurídico y en el seno de la población.

Se destaca, que en una investigación simple, en el sitio de la Cámara de Diputados, se localizó, entre propuestas archivadas y en trámite, la «bagatela» de 52 propuestas de enmienda a la Constitución alterando de

4 «Alardeia-se pela mídia, sem dados, a criminalidade do menor de dezoito anos, dentro de uma visão tacanha da 'lei e da ordem', que de má ou boa-fé crê resolver a questão da criminalidade com repressão penal, como se por um passe de mágica a imputabilidade aos dezesseis anos viesse a reduzir comodamente, sem políticas sociais, a criminalidade». (Reale, 2004, p. 213). Entendiendo que para los medios de comunicación la criminalidad de los niños menores de dieciocho años se resuelve «magicamente» y sin políticas sociales, reduciendo la imputabilidad a la edad de dieciséis años. 
alguna forma la redacción del artículo 228 de la Constitución Federal, ya sea reduciendo la edad penal para 16 años ${ }^{5}$; otro la reducción sería para 12 años $^{6}$; ya, en otras, sería para 14 ańos la edad penal ${ }^{7}$; se propugnó que la imputabilidad penal fuera determinada por el magistrado, en el caso concreto $^{8}$; que la imputabilidad fuera determinada por una junta médica, en los términos de la ley'; en cierta propuesta, la imputabilidad, cuando sea de menores de 18 ańos sería determinada cuando se dé la reincidencia ${ }^{10}$; por fin en otros la reducción de la edad a 16 ańos en caso se cometan crímenes específicos, como crímenes hediondos. ${ }^{11}$

Haciendo uso de una metodología de análisis cualitativa y utilizando los métodos de abordaje hipotético-deductivos de carácter descriptivo y analítico, se buscará hacer una apreciación de la incompatibilidad normativa de la Propuesta de Enmienda a la Constitución N. ${ }^{\circ}$ 171/93 con los principios fundamentales de la Constitución Federal de 1988, resaltando el carácter simbólico de dicha propuesta, así como del aumento del desarraigo estatal, en el caso de la reducción de la edad penal a 16 años.

\section{CONTEXTUALIZACIÓN DEL NúCLEO DE LA CONTIENDA}

Se reafirma el hecho de que la inmadurez natural referente a la edad de 18 años genera acaloradas querellas, viniendo actualmente a dividir a la sociedad en cuanto a la cuestión de la reducción de la mayoría de edad de 18 a 16 ańos, debido al aumento vertiginoso de actos infractores de carácter violento, siendo explotados masivamente por los medios, donde la aplicación de las medidas socioeducativas esculpidas en el ECA están deseando frente a ese anhelo del deseo de «venganza social». ${ }^{12}$

5 Por ejemplo: PEC N.o 426/96; PEC N.o 167/1999; PEC N.o 37/1995; PEC N. . 260/2000; PEC N. ${ }^{\circ}$ 633/1999; PEC N. ${ }^{\circ}$ 531/1997; PEC N. ${ }^{\circ}$ 91/1995; PEC N. ${ }^{\circ}$ 133/1999; PEC N. ${ }^{\circ}$ 179/2003.

6 PEC N. ${ }^{\circ} 302 / 13$; PEC N. $.^{\circ} 345 / 2004$; PEC N. ${ }^{\circ}$ 137/2003.

7 PEC N. ${ }^{\circ}$ 169/1999; PEC N. ${ }^{\circ}$ 242/2004; PEC N. ${ }^{\circ} 399 / 2009$.

$8 \quad$ PEC N. $^{\circ} 125 / 07$; PEC N. $^{\circ} 73 / 2007$; PEC N. ${ }^{\circ} 489 / 2005$.

$9 \quad$ PEC N. ${ }^{\circ} 321 / 2001$.

10 PEC N. ${ }^{\circ} 309 / 2004$.

11 PEC N. ${ }^{\circ} 95 / 92$

12 "Tal presunção, nos dias de hoje, tem gerado revolta na sociedade, que presencia, com impressionante frequência, menores de 18 anos praticando toda sorte de injustos penais, valendo-se, até mesmo, da certeza da impunidade que a sua particular condição lhe proporciona. $\mathrm{O}$ argumento de que ao inimputável por imaturidade natural que pratica um ato infracional 
El debate jurídico que impregna las corrientes conflictivas entre la reducción o no de la mayoría de edad penal tiene en su interior un embate sobre cuál es la naturaleza jurídica de la norma constitucional prescrita en el artículo 228 de la Constitución Federal: «Son penalmente enemigables los menores de dieciocho años, sujetos a las normas de la legislación especial».

La corriente contraria a la reducción de la mayoría de edad argumenta que el contenido normativo del artículo 228 de la Constitución es un derecho individual fundamental, de tal suerte, se constituye en una cláusula pétrea (artículo 60, $\$ 4^{\circ}$ de la Constitución) ${ }^{13}$, que es uno de los límites materiales para la reforma constitucional.

El ala que propugna por la reducción de la mayoría de edad penal a los 16 ańos no vislumbra como derecho fundamental del individuo la materia vehiculada en el artículo 228, pues se encuentra fuera del rol del artículo 5 de la Constitución (título II - de los derechos y garantías fundamentales), donde el constituyente originario destinó específicamente a los derechos y deberes individuales. De tal manera, sería posible la reducción de la mayoría de edad penal que enmendar la Constitución en su disposición 228. ${ }^{14}$

En estos términos es defensor el profesor Guilherme de Sousa Nucci (2009):

A única via para contornar essa situação, permitindo que a maioridade penal seja reduzida, seria através de emenda constitucional, algo perfeitamente possível, tendo em vista que, por clara opçáo do constituinte, a responsabilidade penal foi inserida no capítulo da família, da criança, do adolescente e do idoso, e não no contexto dos direitos e garantias individuais (Capítulo I, artículo $5^{\circ}, \mathrm{CF}$ ).

será aplicada uma medida socioeducativa, nos termos previstos no Estatuto da Criança e do Adolescente (Lei N. ${ }^{\circ} 8.069 / 90$ ), não tem o condão de convencer a sociedade, que cada dia pugna pela redução da maioridade penal para os 16 anos». (Greco, 2011, p. 388).

«Outro ponto profundamente negativo no ECA é a internação máxima por três anos, desprezando-se inclusive o exame criminológico para aferição da cessação ou não da periculosidade. Tal liberalidade representa séria ameaça à coletividade. Imagine-se, apenas para argumentar, um garoto de 13 anos que matou 10 pessoas. Após três anos ele será colocado em liberdade, sob a vigilância dos 'pobres e impotentes' educadores de rua! O que fatalmente ocorrerá é que esse menor reincidirá no infracional». (Fernandes y Fernandes, 2012, p. 432).

13 Constituiçâo Federal. Artículo $60 \ldots$. .... $\$ 4^{\circ}$ Não será objeto de deliberação a proposta de emenda tendente a abolir:

I - a forma federativa de Estado;

II - o voto direto, secreto, universal e periódico;

III - a separação dos Poderes;

IV - os direitos e garantias individuais.

14 Aferir proposta de emenda à constituição de N. ${ }^{\circ} 171$ de 1993 que propõe pela redução da maioridade penal, a qual está em trâmite a 22 anos. 
Não podemos concordar com a tese de que há direitos e garantias humanas fundamentais soltos em outros trechos da Carta, por isso também cláusulas pétreas, inseridas na impossibilidade de emenda prevista no artículo $60, \$ 4^{\circ}$, IV, CF, (...). (pp. 295-296). ${ }^{15}$

Así, también, enseña el profesor Rogério Greco (2011):

Apesar da inserção no texto de nossa Constituição Federal referente à maioridade penal, tal fato não impede, caso haja vontade política para tanto, de ser levada a efeito tal redução, uma vez que o mencionado artículo 228 não se encontra entre aqueles considerados irreformáveis, pois não se amolda ao rol das cláusulas pétreas elencadas nos incisos I a IV, do $\$ 4^{\circ}$, do artículo 60 da Carta Magna.

A única implicação prática da previsão da inimputabilidade penal no texto da Constituição Federal é que, agora, somente por meio de um procedimento qualificado de emenda, a menoridade penal poderá ser reduzida, ficando impossibilitada tal redução via lei ordinária. (p. 389)

Es éste, también, el entendimiento de Miguel Reale Junior (2004):

Entendo que não constitui regra pétrea não por não estar o dispositivo incluído no artículo $5^{\circ}$ da Constituição Federal, referente aos direitos e garantias individuais mencionados no artículo 60, IV, da Constituiçẫo. Não é a regra do artículo 228 da Constituição Federal regra pétrea, pois não se trata de um direito fundamental ser reputado penalmente inimputável até completar dezoito anos. A medida foi adotada pelo Código Penal e depois pela Constituição Federal em face do que se avaliou como o necessário e conveniente, tendo em vista atender aos interesses do adolescente e da sociedade. (p. 212) ${ }^{16}$

Se llama atención que en el parecer de la comisión de constitución y justicia y ciudadanía de la Cámara de Diputados del 31 de marzo de 2015, la cual validó la propuesta de enmienda a la Constitución N. 171 de 1993, cuando la cuestión del artículo 228 ser cláusula pétrea sostuvo que la misma no se

15 «Por isso, a maioridade penal, além de não ser direito fundamental em sentido material (não há notícia de reconhecimento global nesse prisma), também não o é no sentido formal. Assim, não há qualquer impedimento para emenda constitucional suprimindo ou modificando o artículo 228 da Constituiçẫo. Não se pretende, com tal modificação, combater a criminalidade, como muitos pensam. De fato, não é a redução da maioridade penal que poderá solucionar o problema do incremento da prática delitiva no País, embora seja recomendável que isso seja feito para adaptar a lei penal à realidade. $\mathrm{O}$ menor de 18 anos já não é o mesmo do início do século, não merecendo continuar sendo tratado como uma pessoa que não tem noção do caráter ilícito do que faz ou deixa de fazer, sem poder conduzir-se de acordo com esse entendimento». (Nucci, 2009, p. 296).

16 Destaca-se que o professor Miguel Reale, apesar de entender que a regra do artículo 228 da Constituiçẫo Federal, não constitui uma cláusula pétrea, tornando-a, assim, suscetível a modificação, não entende por conveniente a redução da idade penal de $8 \mathrm{anos}$, por uma questão de política criminal. (Véase Reale, M. Instituiçôes de Direito Penal - parte geral. $2^{\circ}$ ed. Rio de Janeiro: Forense, 2004. V. I, p. 212). 
encuadra en ninguna hipótesis de los incisos del $\$ 4^{0}$ del artículo 60 de la Constitución. ${ }^{17}$

Hay una corriente, intermediaria, por así decirlo, que vislumbra la posibilidad de la reducción de la edad de 18 años a 16 años, ya que algunos consideran que no se está aboliendo un derecho fundamental, sino que lo modifica. Es decir, para esa vertiente el límite de edad, en lo que se refiere a la responsabilidad penal, sería un límite garantista al ius puniendi estatal, sólo siendo límite material, la enmienda constitucional, su abolición y no su modificación. ${ }^{18}$

De tal suerte, desde que la actividad del poder constituyente derivado no manche el núcleo esencial de la cláusula pétrea, maculando su esencia, no habría impedimento a su modificación, no constituyéndose así la cláusula pétrea en algo intangible. En estos términos, el núcleo duro de la normatividad del artículo 228 de la Constitución Federal está en la limitación de una edad penal, siendo la edad, en sí, un elemento modificable, a partir de los nuevos valores y realidad social.

El Estatuto de Roma, en el que Brasil es signatario, ${ }^{19}$ que establece el Tribunal Internacional Penal, en su artículo 26, que la edad penal es de 18 ańos:

Artículo 26. O Tribunal não terá jurisdição sobre pessoas que, à data da alegada prática do crime, náo tenham ainda completado 18 anos de idade.

Recuerda al profesor Cezar Roberto Bitencourt (2010, p. 415), que en el Código Penal español de 1996, uno de los más modernos de los países europeos, se elevó la edad del menor de 16 años a 18 años. ${ }^{20}$

17 Disponible en:_https://bit.ly/2LdynkY

18 "(...) para nós é possível a redução de 18 para 16 anos, uma vez que apenas não se admite a proposta de emenda (PEC) tendente a abolir direito e garantia individual. Isso náo significa, como já interpretou o STF, que a matéria náo possa ser modificada.

Reduzindo a maioridade penal de 18 para 16 anos, o direito à inimputabilidade, visto como garantia fundamental, não deixará de existir.

A sociedade evoluiu, e, atualmente, uma pessoa com 16 anos de idade tem total consciência de seus atos, tanto é que exerce os direitos de cidadania, podendo propor a ação popular e votar. Portanto, em nosso entender, eventual PEC que reduza a maioridade penal de 18 para 16 anos é totalmente constitucional. O limite de 16 anos já está sendo utilizado e é fundamentado no parâmetro do exercício do direito de votar e à luz da razoabilidade e maturidade do ser humano (Lenza, 2014, pp. 1357-1358).

19 Decreto N. ${ }^{\circ} 4.388$, de 25 de setembro de 2002 - promulga o Estatuto de Roma do Tribunal Penal Internacional.

20 Francisco Muñoz Conde, ya en los años 80 criticaba la brecha en el sistema legal español con respecto a una ley penal para los menores, donde se utilizan medidas reeducativas en lugar de la sanción: «A falta de um Direito Penal específico para jovens delinquentes (de 16 a 21 
Se destaca, además, la prescripción del artículo 50 del Código Penal Militar ${ }^{21}$ que reconoce la imputabilidad del menor de 18 años y mayor de 16 años cuando se comprobó la capacidad de entendimiento como de la ilicitud de la conducta perpetrada, aplicando, sin embargo, la pena de forma disminuida. Basta decir que dicho dispositivo no fue recibido por la Constitución de 1988, no manifestando eficacia.

Genival Veloso (2008) es refractario la idea de reducción de la mayoría de edad penal, apuntando el equívoco de analizar la figura del criminal por la edad. Sobre la temática así diserta:

Ultimamente, quase de maneira obstinada, vem-se tentando reduzir a inimputabilidade para 16 anos, justificando-se pela mudança de mentalidade que o jovem brasileiro sofreu nestes últimos anos. Mesmo assim, é evidente que não compartilhamos com essa idéia, pois o que se pretende náo é comprometê-lo com a nova realidade ou antecipar-lhes a responsabilidade, mas tão-só «mandá-los mais cedo para a cadeia». O fato de encarar a criminalidade pelo prisma da idade é um equívoco. Outro fato propalado pelos defensores do endurecimento das medidas aos jovens infratores é o aumento do tempo de internamento, hoje fixado em três anos, com limite em 21 anos de idade para sua liberação. Se analisarmos melhor, veremos que, para um adulto cumprir uma pena em penitenciárias por 3 anos, teria ele sua pena situada em tomo de 18 anos de reclusão, e depois de cumprido $1 / 6$ da pena terá o direito de deixar o cárcere. Três anos de internamento para um adolescente ê tempo bastante para se fazer algo de bom em favor de sua ressocialização e reintegração nos meios familiar e social.

(...)

Certo é que o jovem e mesmo a criança têm o necessário discernimento de saber desde cedo que muitas coisas sáo reprováveis como furtar ou matar. E por que não submetê-los também ao rigor da legislação penal? Por um fato muito simples: é inconveniente e perverso colocar essas crianças e esses adolescentes no mesmo sistema penitenciário. Resulta inconvenientes aos programas de prevenção e repressão da criminalidade: submetê-los a um sistema que já é inviável e ineficaz para os próprios adultos.

anos) é uma das mais lamentáveis lacunas do ordenamento jurídico espanhol. A Proposta de Anteprojeto de 1983 fixa a maioridade penal em 18 anos (artículo 22, \$39) e prevê a adoção de medidas reeducativas substitutivas da pena para menores entre dezoito e vinte e um anos (artículo 99) e a criação de um Direito Penal juvenil». (Muñoz, 1988, p. 140).

21 Código Penal Militar. Artículo 50. O menor de dezoito anos é inimputável, salvo se, já tendo completado dezesseis anos, revela suficiente desenvolvimento psíquico para entender o caráter ilícito do fato e determinar-se de acôrdo com êste entendimento. Neste caso, a pena aplicável é diminuída de um têrço até a metade. 
O que está faltando é o cumprimento das regras constitucionais em favor da criança e do adolescente, por meio de políticas sociais apropriadas em que eles possam desenvolver-se normalmente. A verdade é que não existem políticas públicas para dar a estes adolescentes oportunidades de vida. (Franca, p. 433). ${ }^{22}$

Contra el habla, arriba presentada, es difícil rebatir frente a la lógica irretroquible y del sentido de humanidad que se siente.

\section{POR UN DISCURSO REFRACTARIO LA REDUCCIÓN DE LA EDAD PENAL}

\subsection{De los estatus de los derechos fundamentales: el de- sarrollo de la función limitadora de la Constitución}

Jellinek explicita los cuatro estatus de los derechos fundamentales: estado pasivo, estado activo, estado negativo y estatus positivo. ${ }^{23}$

Es de importancia nuclear, la temática hora propuesta, la figura del estatus negativo ${ }^{24}$, la cual se refiere a un espacio de libertad del que goza el individuo contra las injerencias de la actividad estatal.

De tal suerte, los derechos fundamentales esculpidos en la carta constitucional serían limitadores de la actuación estatal, con relación al ciudadano, envolviéndose en arbitrariedad cuando no es respetada.

22 «Os adolescentes são muito mais vítimas de crimes do que autores, contribuindo este fato para a queda da expectativa de vida no Brasil, pois se existe um «risco Brasil», este reside na violência da periferia das grandes e médias cidades. Dado impressionante é o de que $65 \%$ dos infratores menores vivem em família desorganizada, junto com a máe abandonada pelo marido, que por vezes tem filhos de outras uniōes também desfeitas, e lutam para dar sobrevivência à sua prole. (Reale, 2004, p. 213)».

23 «No final do século XIX, Jellinek desenvolveu a doutrina dos quatro status em que o indivíduo pode encontrar-se em face do Estado. Dessas situaçôes, extraem-se deveres ou direitos diferenciados por particularidades de natureza». (Mendes, Coelho y Branco, 2009, p. 289).

24 "O status negativo em sentido estrito $e$ original de Jellinek diz respeito exclusivamente a liberdades jurídicas não-protegidas. O status negativo em sentido amplo — que extrapola a sistemática de Jellinek - diz respeito aos direitos a açóes negativas do Estado (direitos de defesa), que protegem o status negativo em sentido estrito. Ao status positivo em sentido amplo pertencem direitos tanto a açôes positivas quanto a ações negativas. Já ao status positivo em sentido estrito pertencem somente direitos a ações positivas. As conseqüências sistemáticas dessa divisão para o sistema de Jellinek são simples e claras. Os direitos que são acrescentados ao status negativo em sentido estrito para que se possa convertê-lo em um status negativo em sentido amplo (direitos de defesa) são uma subespécie dos direitos do status positivo em sentido amplo». (Alexy, 2008, p. 267). 
Es decir, las normas constitucionales, tenidas como derechos fundamentales, serían un haz de derechos constituyentes de un nivel ético mínimo civilizatorio, donde cualquier norma infraconstitucional que así no se subsuma a ese ámbito ético basilar será una norma eivada con la inconstitucionalidad, debiendo tener su propia la invalidez decretada, siendo expurgada del sistema jurídico vigente.

\subsection{De la constitucionalización del derecho de los niños y adolescentes}

En vista de la doctrina de la protección integral, que permeó la década de 1980, fruto de las normativas de las Naciones Unidas, se tiene con la Constitución de 1988 la constitucionalización de premisas normativas en lo que concierne al bojo del derecho de los niños y adolescentes.

Es decir, tiene un microsistema jurídico de protección a los niños y a los adolescentes, sean ellos menores infractores o no, constituyendo un haz normativo protectivo que limita la intervención Estatal y al mismo tiempo acarrea el deber del Estado en relación a la prestación positiva, generando derecho subjetivo a los niños y adolescentes.

Es con ese alcance que se dio la redacción del artículo 227 de la Constitución Federal, con destaque a su $₫ 3^{\circ}$ :

Artículo 227. É dever da família, da sociedade e do Estado assegurar à criança, ao adolescente e ao jovem, com absoluta prioridade, o direito à vida, à saúde, à alimentação, à educação, ao lazer, à profissionalização, à cultura, à dignidade, ao respeito, à liberdade e à convivência familiar e comunitária, além de colocá-los a salvo de toda forma de negligência, discriminação, exploração, violência, crueldade e opressão.

$\$ 3^{\circ} \mathrm{O}$ direito a proteção especial abrangerá os seguintes aspectos:

I - idade mínima de quatorze anos para admissão ao trabalho, observado o disposto no artículo 7º, XXXIII;

II - garantia de direitos previdenciários e trabalhistas;

III - garantia de acesso do trabalhador adolescente e jovem à escola;

IV - garantia de pleno e formal conhecimento da atribuição de ato infracional, igualdade na relaçáo processual e defesa técnica por profissional habilitado, segundo dispuser a legislação tutelar específica;

$\mathrm{V}$ - obediência aos princípios de brevidade, excepcionalidade e respeito à condição peculiar de pessoa em desenvolvimento, quando da aplicaçẫo de qualquer medida privativa da liberdade; 
VI - estímulo do Poder Público, através de assistência jurídica, incentivos fiscais e subsídios, nos termos da lei, ao acolhimento, sob a forma de guarda, de criança ou adolescente órfăo ou abandonado;

VII - programas de prevenção e atendimento especializado à criança, ao adolescente e ao jovem dependente de entorpecentes e drogas afins.

En el artículo anterior de la Constitución se tiene un conjunto de derechos fundamentales específicos a la persona vulnerable, que es el niño y el adolescente, los cuales vienen por agregar, y no excluir, los demás derechos fundamentales de la persona humana, como, vg, los encampados en el mismo, el arte 5 de la Carta Constitucional.

Es con ese espíritu de protección integral, impregnado en la norma constitucional, destinado a las personas de los niños y adolescentes, los cuales están en proceso de formación y maduración, que se concibe la inimputabilidad penal de los menores de 18 años como un derecho fundamental, de estatus negativo, de los niños y de los adolescentes, como poder de castigar al Estado.

Es fundamental destacar que la Constitución brasileña es vanguardista en varios aspectos, uno de ellos es exactamente la especificación cronológica de la inimputabilidad como garantía constitucional, no habiendo un dispositivo similar en las Constituciones brasileñas pasadas.

Não se pactua com o entendimento de que os direitos fundamentais se restringe ao âmbito do artículo $5^{\circ}$ da Constituiçáo, ${ }^{25}$ só ficando o Estado limitado em sua intervenção, na esfera de espaço do cidadão, ao conteúdo desse artigo, pois a essência máxima das Constituiçóes modernas, pós-revoluçáo francesa, é a limitação do poder estatal, pois esse sempre tendeu abusar, formando, ao longo da história direitos valorados como fundamentais.

La libertad es un derecho como prerrogativa fundante del ciudadano. El artículo 228 de la Constitución está limitando la intervención del Estado en esa esfera de libertad, al impedir el castigo penal a menores de 18 años. No se vislumbra como esa normatividad del artículo 228 no puede considerarse un derecho fundamental.

En ese sentido corrobora el pensamiento de Karyna Batista Sposato (2011):

25 «A propósito, foi dito que apesar de as normas (arts. 227 e 228) se encontrarem no Capítulo VII do Título VIII da Constituição, não há como negar-lhes a natureza análoga aos direitos, liberdades e garantias fundamentais». (Canotilho, Leoncy, Mendes, Sarlet y Streck, 2013, p. 2138). 
(...) não é necessário que o direito ou garantia individual esteja expressamente descrito no artículo $5^{\circ}$ da CF/1988 para impedir a deliberação da proposta. Basta que esteja no texto constitucional como um direito ou garantia que diga respeito diretamente à vida, à liberdade, à igualdade e até mesmo à propriedade, e que no caput do citado artículo $5^{\circ}$ venha reforçado por uma cláusula de inviolabilidade. (p. 671).

Dotti (2010), sobre la inimputabilidad como garantía fundamental aduce:

A inimputabilidade assim declarada constitui uma das garantias fundamentais da pessoa humana, embora topograficamente náo esteja incluída no respectivo Título (II) da Constituição que regula a matéria. Trata-se de um dos direitos individuais inerentes à relação do artículo $5^{\circ}$, caracterizando, assim, uma cláusula pétrea. Consequentemente, a garantia não pode ser objeto de emenda constitucional visando à sua abolição para reduzir a capacidade penal em limite inferior de idade — dezesseis anos, por exemplo, como se tem cogitado. A isso se opóe a regra do $\$ 4^{\circ}$, IV, do artículo 60 da CF. (p. 496).

También, no se refiere la llamada "corriente intermedia», el cual defiende la reducción de la mayoría de edad penal a 16 años, pues no se trata de abolir el derecho fundamental, sino modificarlo.

Cuando se propugna la reducción de la mayoría de edad penal para una edad inferior a 18 años se está dañando el núcleo duro de esa cláusula pétrea, pues por más que no se esté aboliendo, se está ampliando considerablemente la esfera de injerencia penal del Estado en el ámbito de libertad del ciudadano.

Con ese simple simplismo de afirmar la tesis de la reducción de la imputabilidad penal a 16 años, pues no se estaría por abolir, sino sólo por modificar, se pregunta, ¿por qué no reducir a 14 años, como en algunos países de Europa? ¿Y por qué no para 12 años? Si redujo la edad penal a 8 años no se elimina la premisa garantista constitucional, sino sólo se modifica.

En este caso, el argumento de la argumentación jurídica, en el caso en tela, de hecho sería válido cuando se propugna por el aumento de la edad penal, como por ejemplo, 21 años, pues en ese caso, el núcleo duro del derecho fundamental estaría siendo de hecho respetado, porque se iba a aumentar aún más el alcance del poder de persecución penal, siendo concordante con la doctrina de la protección integral que inspiró el proceso de constitucionalización del derecho de los niños y de los adolescentes. 
Se asocia las palabras de Jorge Figueiredo Dias (2007), cuando diserta que la barrera etarea para intervención penal del Estado se da por una cuestión de humanidad: ${ }^{26}$

(...) a colocação desta barreira etária intransponível à intervenção penal funda-se - em estrita perspectiva político-criminal - em um princípio de humanidade que deve caracterizar todo o direito penal de um Estado de direito material. Deve evitar-se a todo o custo a submissáo de uma criança ou adolescente às sançóes mais graves previstas no ordenamento jurídico e ao rito do processo penal, pela estigmatizaçáo que sempre acompanha a passagem pelo corredor da justiça penal e pelos efeitos extremamente gravosos que a aplicaçáo de uma pena necessariamente produz ao nível dos direitos de personalidade do menor, marcando inevitavelmente o seu crescimento e toda a sua vida futura. Ao que acrescem outras razóes. Por um lado, a necessidade - a que o nosso CP oferece base legal no artículo $20^{\circ}-3$ e que, como vimos no $\$ 51$, é directamente relevante para outros efeitos — de compreensão da pena pelo agente e, consequentemente, de poder ser por ela influenciado no sentido da sua socializaçáo. E, por outro lado, mas na mesma direcçáo, a inidoneidade da pena, especialmente da pena de prisão, para realizar essa finalidade de (re)socializaçáo do delinquente menor. É em relação aos menores, dado serem particularmente influenciáveis e se encontrarem numa situação de especial vulnerabilidade, que mais se fazem sentir os efeitos criminógenos da pena de privação da liberdade, que, as mais das vezes, não promoverá a sua reinserçáo social, mas poderá antes contribuir para a sua dessocializaçáo, integrando-os definitiva e irremediavelmente no «mundo do crime». (pp. 595 y 596).

\subsubsection{Del nivel constitucional de la Convención sobre derechos del niño - integrante del bloque de constitucionalidad}

La materia sobre tratados internacionales sufrió un nuevo modelado a partir de la reforma promovida por la Enmienda Constitucional N. ${ }^{\circ}$ $45 / 04$, la cual se conoció como «reforma del poder judicial», ańadiendo el $\$ 3^{\circ}$, en el artículo $5^{\circ}$, con la siguiente prescripción:

Artículo 5. (...)

$\$ 3^{\circ}$ Os tratados e convençóes internacionais sobre direitos humanos que forem aprovados, em cada Casa do Congresso Nacional, em dois turnos, por três quintos dos votos dos respectivos membros, serão equivalentes às emendas constitucionais.

26 Poderiam questionar a validade da presente citação, tendo em vista que no sistema jurídico penal português adota-se a idade penal de 16 anos, a mesma propugnada na PEC N. ${ }^{\circ} 171 / 93$. Todavia, deve-se lembrar que a inimputabilidade penal cronológica não fora elevada ao status constitucional. 
Además, en 2006, por medio del Recurso Extraordinario N. ${ }^{\circ} 466.343$ / SP, el Supremo Tribunal Federal (STF) completa ese proceso de rediseńo del derecho de los tratados. En adelante, es fundamental definir la figura del tratado internacional.

El tratado internacional sería un acuerdo escrito entre los Estados u organizaciones internacionales sobre un asunto de interés común, regido por el Derecho internacional, que puede contener dos o más documentos, como anexos y protocolos, donde éstos auxilian en la reglamentación del documento principal. ${ }^{27}$

Los tratados internacionales, así es conceptuado por Valério Mazzuoli (2007):

(...). Portanto, sob o aspecto que ora nos ocupa, entende-se por tratado todo acordo formal, concluído entre os sujeitos de Direito Internacional Público, regido pelo direito das gentes e visando à produção de efeitos de direito para as partes contratantes. (p.133)

En la jurisprudencia del STF, la consolidación de la teoría de la equivalencia legislativa entre los tratados internacionales y las leyes ordinarias, es decir, los tratados internacionales, ratificados por el Congreso Nacional, adentraron en el sistema jurídico brasileño con estatus de ley ordinaria. Esta teoría prevaleció por más de tres décadas en la jurisprudencia del STF.

A partir de una decisión, en el marco de un recurso extraordinario (RE N. ${ }^{\circ}$ 466343/SP, rel. Min. Cezar Peluso, 22.11.2006) ${ }^{28}$, al tratar de la prisión

27 Assim encontra-se definido a figura do tratado na Convençấo de Viena sobre o direito dos tratados, firmado em 1969: «'tratado' significa um acordo internacional concluído por escrito entre Estados e regido pelo Direito Internacional, quer conste de um instrumento único, quer de dois ou mais instrumentos conexos, qualquer que seja sua denominação específica».

28 «Em seguida, o Min. Gilmar Mendes acompanhou o voto do relator, acrescentando aos seus fundamentos que os tratados internacionais de direitos humanos subscritos pelo Brasil possuem status normativo supralegal, o que torna inaplicável a legislaçáo infraconstitucional com eles conflitantes, seja ela anterior ou posterior ao ato de ratificaçáo e que, desde a ratificaçáo, pelo Brasil, sem qualquer reserva, do Pacto Internacional dos Direitos Civis e Políticos (artículo 11) e da Convençáo Americana sobre Direitos Humanos - Pacto de San José da Costa Rica (artículo 70, 7), náo há mais base legal para a prisão civil do depositário infiel. Aduziu, ainda, que a prisão civil do devedor-fiduciante viola o princípio da proporcionalidade, porque o ordenamento jurídico prevê outros meios processuais-executórios postos à disposição do credor-fiduciário para a garantia do crédito, bem como em razão de o DL 911/69, na linha do que já considerado pelo relator, ter instituído uma ficção jurídica ao equiparar o devedor-fiduciante ao depositário, em ofensa ao princípio da reserva legal proporcional. Após os votos dos Ministros Cármen Lúcia, Ricardo Lewandowski, Joaquim Barbosa, Carlos Britto e Marco Aurélio, que também acompanhavam o voto do relator, pediu vista dos autos o Min. Celso de Mello». (RE-466343) (Énfasis agregado). Informativo N. ${ }^{\circ}$ 449, de 20 a 24 de novembro de 2006 do STF. (Énfasis agregado). 
civil del depositario infiel, previsto en el artículo 5, LXVII y su análisis conforme a la Convención Americana de Derechos Humanos, reconoció que tratados internacionales de derechos humanos que no fueron aprobados con el quórum de $3 / 5$, en dos turnos, en cada casa del congreso (procedimiento respectivo de las enmiendas constitucionales) portar el estatus normativo de supralegalidad. Es decir, arriba en la ley ordinaria y por debajo de la norma constitucional.

De tal suerte, en materia de tratados internacionales, se tienen las siguientes equivalencias: tratados internacionales que no sean de derechos humanos se adhieren al nivel de ley ordinaria; los tratados internacionales de derechos humanos que cumplen la regla del artículo $5^{\circ}, \$ 3$ de la Constitución, tendrían estado de enmiendas a la constitución; por último, tratados internacionales de derechos humanos, no aprobados según los trámites de enmienda constitucional, tendrían el porte de dispositivos supralegales.

Figura 1. Jerarquía de los dispositivos normativos.

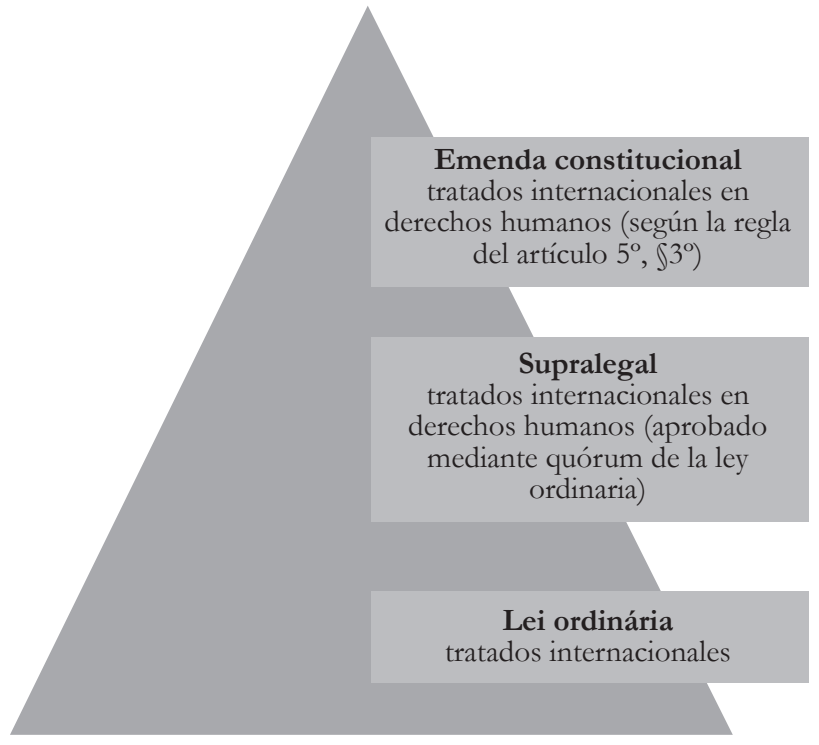

Fuente: Elaboración propia.

Se dice que hasta la presente fecha, el único tratado / convención internacional ratificado según la regla constitucional del artículo, en el caso de las personas con discapacidad y su protocolo facultativo, firmados en Nueva York, el 30 de marzo de 2007, es promulgado a través del Decreto N. ${ }^{\circ} 6.949$ / 09. 
Recordar la enseñanza de la profesora Flávia Piovesan, quien, al interpretar el $\$ 2^{\circ}$ del artículo De la Constitución Federal, entiende que los tratados internacionales de protección a los derechos humanos, independientemente del quórum de aprobación ser de Enmienda Constitucional, vienen por incorporarse al sistema jurídico brasileńo con estatus de norma constitucional en cara, entre otras cosas, del carácter materialmente constitucional de los derechos fundamentales, viniendo tales tratados, especialmente aquellos anteriores a la EC N. ${ }^{\circ} 45 / 04$, a componer el bloque de constitucionalidad del orden brasileño. ${ }^{29}$

Sigue a lapidar lección de la profesora Flávia Piovesan (2015):

Ao efetuar a incorporaçáo, a Carta atribui aos direitos internacionais uma natureza especial e diferenciada, qual seja, a natureza de norma constitucional. Os direitos enunciados nos tratados de direitos humanos de que o Brasil é parte integram, portanto, o elenco dos direitos constitucionalmente consagrados. Essa conclusão advém ainda de interpretação sistemática e teológica do Texto, especialmente em face da força expansiva dos valores da dignidade humana e dos direitos fundamentais, como parâmetros axiológicos a orientar a compreensão do fenômeno constitucional. (p. 124).

En esta óptica interpretativa, la Convención sobre los Derechos del Niño, promulgada por el decreto $\mathrm{N} .^{\circ} 99.710 / 90$, tendría estatus de norma constitucional, independientemente de la obediencia del quórum calificado, determinado en el artículo. De acuerdo con lo dispuesto en el artículo de la Constitución, constituyendo el plexo de derechos fundamentales teniendo en cuenta el carácter especial de esos tratados que remite diversas obligaciones entre el Estado y el ciudadano, en atención al principio de la prevalencia de la norma más favorable, consolidando así la visión Constitución como un orden jurídico fundamental abierto.

Además, por tratarse de derechos y garantías fundamentales de la persona, la Convención, supra, tiene aplicación inmediata, de conformidad con el artículo de la Constitución Federal, lo que acarrea la innecesidad de legislación infraconstitucional para darle eficacia, ya constituyendo, desde ahora, derecho subjetivo del ciudadano pasible de exigibilidad.

29 «A Constituição de 1988 recepciona os direitos enunciados em tratados internacionais de que o Brasil é parte, conferindo-lhe natureza de norma constitucional. Isto é, os direitos constantes nos tratados internacionais integram e complementam o catálogo de direitos constitucionalmente previsto, o que justifica estender a esses direitos o regime constitucional conferido aos demais direitos e garantias fundamentais». (Piovesan, 2015, p. 124). 
A incorporação automática do Direito Internacional dos Direitos Humanos pelo direito brasileiro — sem que se faça necessário um ato jurídico complementar para sua exigibilidade e implementaçáo - traduz relevantes consequências no plano jurídico. De um lado, permite ao particular a invocação direta dos direitos e liberdades internacionalmente assegurados, e, por outro, pró́be condutas e atos violadores a esses mesmos direitos, sob pena de invalidaçáo. Consequentemente, a partir da entrada em vigor do tratado internacional, toda norma preexistente que seja com ele incompatível perde automaticamente a vigência». Ademais, passa a ser recorrível qualquer decisão judicial que violar as prescriçóes do tratado - eis aqui uma das sançóes aplicáveis na hipótese de inobservância dos tratados (Piovesan, 2015, p. 156). ${ }^{30}$

\subsubsection{Principios constitucionales sensibles}

\section{En el marco de la Convención sobre los Derechos del Niño (Decreto N. ${ }^{\circ}$ $99.710 / 90)$, sin mayores asombros se trata de una materia clasificada como de derechos humanos, que tiene el estatus de los derechos humanos, principio constitucional sensible.}

Artículo 34. A União não intervirá nos Estados nem no Distrito Federal, exceto para:

VII - assegurar a observância dos seguintes princípios constitucionais:

a) forma republicana, sistema representativo e regime democrático;

b) direitos da pessoa humana;

c) autonomia municipal;

d) prestação de contas da administração pública, direta e indireta.

e) aplicação do mínimo exigido da receita resultante de impostos estaduais, compreendida a proveniente de transferências, na manutenção e desenvolvimento do ensino e nas ações e serviços públicos de saúde. (Énfasis agregado).

De tal suerte, sólo se puede reconocer como derecho de la persona humana con edad inferior a 18 ańos de ser procesado y responsabilizado por una legislación especial, distinta de aquella aplicada a los mayores de 18 años (Sposato, 2011, p. 672).

30 «Em outras palavras, não será mais possível a sustentação da tese segundo a qual, com a ratificação, os tratados obrigam diretamente aos Estados, mas não geram direitos subjetivos para os particulares, enquanto não advém a referida intermediação legislativa. Vale dizer, toma-se possível a invocação imediata de tratados e convençốes de direitos humanos, dos quais o Brasil seja signatário, sem a necessidade de ediçấo de ato com força de lei, voltado à outorga de vigência interna aos acordos internacionais». (Piovesan, 2015, p. 156). 


\subsection{De la normatividad constitucional simbólica de la Pro- puesta de Enmienda Constitucional (PEC) N. $.^{\circ} 171 / 93$}

Marcelo Neves escribe sobre el constitucionalismo simbólico, a partir de la teoría tricotómica de Kindermann, diserta que el contenido de la legislación simbólica versa sobre la confirmación de valores sociales; demostración de la capacidad de acción del Estado; y la postergación de soluciones de conflictos sociales a través de comportamientos dilatorios (Neves, 2007, p. 33).

Así, el gran catedrático define legislación simbólica:

Considerando-se que a atividade legiferante constitui um momento de confluência concentrada entre sistemas político e jurídico, pode-se definir a legislaçáo simbólica como produçáo de textos cuja referência manifesta à realidade é normativo-jurídica, mas que serve, primária e hipertroficamente, a finalidades políticas de caráter náo especificamente normativo-jurídico. (Neves, 2007, p. 30).

En el caso de la PEC N. ${ }^{\circ} 171 / 93$, se vislumbra el carácter simbólico, cuyo contenido está inmerso en estas tres situaciones descritas por Marcelo Neves, a pesar de la predominancia mayor de la «demostración de la capacidad de acción del Estado».

En la «confirmación de valores sociales» hay el conflicto de valores entre grupos, cuya aprobación de determinada disposición legislativa representa «victoria» y demuestra su «superioridad» en relación a los demás, quedando en segundo plano la eficacia normativa ${ }^{31}$.

Esto sucede en el desarrollo de la PEC N. ${ }^{\circ} 171 / 93$, la cual está impregnada de los valores oriundos del movimiento de la «ley y orden» que predica por

31 «Nesses casos, os grupos que se encontram envolvidos nos debates ou lutas pela prevalência de determinados valores vêem a 'vitória legislativa' como uma forma de reconhecimento da 'superioridade' ou predominância social de sua concepção valorativa, sendo-lhes secundária a eficácia normativa da respectiva lei. Dessa maneira, procuram influenciar a atividade legiferante, no sentido de que sejam formalmente proibidas aquelas condutas que náo se coadunam com os seus valores, assim como permitidos ou obrigatórios os comportamentos que se conformam aos seus padrôes valorativos, satisfazendo-se as suas expectativas basicamente com a expedição do ato legislativo.» (Neves, 2007, p. 33). "Outro caso consiste na discussão que se desenvolve sobre o aborto na Alemanha, especialmente a partir dos anos setenta. Blankenburg enfatiza que os participantes da discussão em tomo da legalização do aborto estão informados de que as violaçôes do $\$ 218$ do Código Penal Alemão (StGB) 'são muito freqüentes e que punições ocorrem apenas em casos excepcionais'. Conclui, então, com base inclusive em decisões do Tribunal Constitucional Federal, que no conflito sobre a legalização do aborto trata-se da 'confirmação simbólica de pretensôes normativas', e não da 'imposição efetivà dessas». (Neves, 2007, p. 34). 
la criminalización de conductas insignificantes y el severo aumento de las penalidades privativas de libertades, propugnando, incluso por penas de carácter perpetuo y de muerte. En el otro lado de la mesa está el ala de los garanteístas que defienden un Derecho Penal Mínimo en obediencia a los principios basilares de la intervención mínima y de la fragmentación, donde el ius puniendi estatal sólo se legitima dentro de los valores constitucionales.

En cuanto a la «postergación de soluciones de conflictos sociales a través de comportamientos dilatorios», explicita el profesor supra, que darse cuando de la divergencia entre grupos políticos se tiene la aprobación consensuada del acto legislativo, el cual no gira la desavenencia, pero transfiere el conflicto para un momento futuro indeterminado, confiando en la ineficacia normativa. ${ }^{32}$

En el presente estudio no se vislumbra la convergencia entre los grupos políticos («Ley y orden»y «garantistas») para la aprobación de la PEC N. ${ }^{\circ}$ 171/93; sin embargo, hay una postergación para el futuro que es el problema de la violencia causada por el menor, es cristalino que la reducción de la mayoría de edad penal a 16 ańos no resolverá este serio problema social. La ineficacia normativa es apremiante y algún agente político sabe y estar contando con eso.

Por último, en la situación de la «demostración de la capacidad de acción del Estado», también llamada «legislación-coartada» se tiene la creación normativa en la respuesta a un hecho social que generó un alarde o estado de emergencia en la población, el no-dispositivo legislativo justifica el hacer del Estado, buscando producir confianza en el ámbito jurídico y político, teniendo una fuerte repercusión en la mina electoral.

Em face da insatisfação popular perante determinados acontecimentos ou da emergência de problemas sociais, exige-se do Estado muito freqüentemente uma reação solucionadora imediata. Embora, nesses casos, em regra, seja improvável que a regulamentação normativa possa contribuir para a solução dos respectivos problemas, a atitude legiferante serve como um álibi do legislador perante a população que exigia uma reação do Estado. (Neves, 2007, p. 37).

32 «Nesse caso, as divergências entre grupos políticos não são resolvidas por meio do ato legislativo, que, porém, será aprovado consensualmente pelas partes envolvidas, exatamente porque está presente a perspectiva da ineficácia da respectiva lei. $\mathrm{O}$ acordo não se funda então no conteúdo do diploma normativo, mas sim na transferência da solução do conflito para um futuro indeterminado». (Neves, 2007, p. 41). 
Este contenido de «legislación-coartada» está en el centro de la PEC N. 171/93. Es una respuesta del Estado al factor de violencia alardeado y explotado por los medios de forma sensacionalista e irresponsable, donde se ve un claro contenido ideológico. Se trata de vender una ilusión de la solución con relación a uno de los aspectos de la violencia urbana (actos infractores perpetrados por niños y adolescentes), en la creencia de que los actos legislativos son capaces de modificar la realidad, desconsiderando las interferencias de un acto de las variables no normativas indispensables ${ }^{33}$.

\subsubsection{Del Derecho Penal simbólico}

No se tiene duda de que al intentar reducir la edad penal a 16 años se esta ante un derecho penal simbólico, el cual no surtirá el efecto deseado: la reducción de la criminalidad. Una vez más se quiere usar el Derecho Penal para remendar la omisión e ineficacia en la implantación de las políticas públicas debidas en escalofrío a los dictámenes constitucionales ${ }^{34}$.

33 «A legislação-álibi decorre da tentativa de dar a aparência de uma solução dos respectivos problemas sociais ou, no mínimo, da pretensão de convencer o público das boas intenções do legislador. Como se tem observado, ela não apenas deixa os problemas sem solução, mas além disso obstrui o caminho para que eles sejam resolvidos. A essa formulação do problema subjaz uma crença instrumentalista nos efeitos das leis, conforme a qual se atribui à legislação a função de solucionar os problemas da sociedade. Entretanto, é evidente que as leis não são instrumentos capazes de modificar a realidade de forma direta, pois as variáveis normativo-jurídicas defrontam-se com outras variáveis orientadas por outros códigos e critérios sistêmicos (...). A resolução dos problemas da sociedade depende da interferência de variáveis não normativo-jurídicas. Parece, portanto, mais adequado afirmar que a legislação-álibi destina-se a criar a imagem de um Estado que responde normativamente aos problemas reais da sociedade, embora as respectivas relaçôes sociais não sejam realmente normatizadas de maneira conseqüente conforme o respectivo texto legal». (Neves, 2007, p. 39).

34 «É notória a situaçáo incompatível ou irregular da criança e do adolescente nos países onde o poder público não cumpre sua função social, máxime no que tange À assistência familiar». (Fernandes y Fernandes, 2012, p. 424). «Enfim, para se admitir a redução da idade para a »responsabilidade penal», exige-se competência e honestidade de propósitos, aspectos nada comuns no tratamento do sistema repressivo penal brasileiro como um todo. Aliás, a incompetência e a falta de seriedade no trato dessas questôes têm sido a tônica da nossa realidade político-criminal. Por isso, temos, inclusive, receio de sustentar essa tese, porque os nossos legisladores poderão gostar da ideia, mas, como sempre acontece no Brasil, aproveitá-la somente pela metade, ou seja, adotar essa responsabilidade penal diminuída e "esquecer» de criar os «estabelecimentos adequados», exclusivos para os menores, com a estrutura funcional indispensável (com técnicos especializados)! Ademais, essa tese não pode ser desenvolvida satisfatoriamente neste espaço, $\mathrm{e}$ muito menos executada pela metade». (Bitencourt, 2010, p. 415). 
No será con el uso de la sanción penal que se combatirán los actos antisociales de los menores, pues no será a partir de la reclusión que se implementará el acceso a la educación, la salud, la seguridad en todos sus aspectos, la promoción del desarrollo los miles de menores que se alojan en la calle, siendo apuntados por valores morales distorsionados cuando el proceso de formación y desarrollo. ${ }^{35}$

E entre todos fatores exógenes da criminalidade desponta em primeiro lugar a miséria. A miséria é a principal razão dos atos infracionais dos menores. (Fernandes y Fernandes, 2012, p. 425)

Sobre esta temática el Ministro de Justicia, Francisco Campos, en la exposición de motivos de la parte general del Código Penal de 1940 que la formación del carácter del menor de 18 años debe ser dada con educación en lugar del uso del Derecho Penal:

Os que preconizam a redução do limite, sob a justificativa da criminalidade crescente, que a cada dia recruta maior número de menores, não consideram a circunstância de que o menor, ser ainda incompleto, é naturalmente antissocial na medida em que não é socializado ou instruído. O reajustamento do processo de formação do caráter deve ser cometido à educação, não à pena criminal. ${ }^{36}$

Se tiene un verdadero engaño, ya que el menor infractor es estigmatizado por los medios, sirviendo de chivo expiatorio al problema generalizante de la creciente violencia.

Es con clarividencia que la reducción de la menor edad penal no contendrá la problemática de la violencia, teniendo serios riesgos de aumento, aún más, de la criminalidad, ${ }^{37}$ en el sentido de «efecto colateral» de la norma

35 «Não fosse o fato de existirem centenas de milhares de meninas atiradas à prostituição na faixa etária de 9 a 15 anos de idade, não fosse o alto percentual de meninos e meninas vivendo ou morando nas ruas, não fosse a deletéria adultização precoce da criança, tudo conduzindo o menor à marginalizaçáo, restaria o nocivo exemplo da pulverizaçáo dos valores morais incentivada e até imposta pela má imprensa escrita, falada e televisada, principalmente por seu prestígio persuasório.». (Fernandes y Fernandes, 2012, p. 424).

36 Exposiçấo de motivos da redação primeira da parte geral do Código Penal.

37 «No plano do direito penal, fala-se da função ou efeito criminógeno da própria lei penal. Poder-se-ia objetar que se trata aqui de um caso de antiefetividade. Mas a hipótese é mais abrangente. A pesquisa criminológica aponta situaçôes em que a atuaçấo coercitiva do aparelho estatal contra a criminalidade juvenil leva a estreitar os laços entre os respectivos jovens, que, em reação, passam a praticar atos puníveis mais graves. Em muitos casos, à promulgação de uma nova lei penal seguem-se contra-reaçôes, atos de resistência e de ajuda aos autores, implicando outras condutas puníveis.». (Neves, 2007, p. 49). 
constitucional enmendada, respondiendo tan sólo al carácter ideológico de un sector de la política, transfiriendo al Estado la satisfacción de la «venganza» por el injusto, en contraposición a los antiguos procesos de linchamiento población. (Neves, 2007, p. 50). ${ }^{38}$

En estos términos sigue la disertación de Ney Moura Teles (2006):

Propostas como essas, longe de resolver qualquer problema da espécie existente no país, constituem verdadeiro engodo, e só podem ser compreendidas dentro da ideologia da corrente da lei e da ordem.

As crianças e os adolescentes que cometem fatos típicos e ilícitos, que são usados por delinqüentes adultos, são, em verdade, filhos de uma sociedade injusta, assentada em bases econômicas e sociais perversas. A eles não foram proporcionadas oportunidades de vida digna, com habitação, família, educação, saúde, lazer, formação moral, enfim, não tiveram oportunidades de apreender os valores ético-sociais importantes e, por isso, quando atuam contra o direito, estão, na verdade, simplesmente, respondendo aos «cidadãos de bem» com o gesto que aprenderam: a violência e o desrespeito à lei.

Nunca se pode esquecer que náo é o Direito Penal o purificador das almas, nem sua missáo é a de combater a violência, adulta ou juvenil. Sua tarefa é proteger os bens jurídicos mais importantes, das lesôes mais graves. (pp. 298 y 299).

\section{UN BREVE RETRATO DE LA REALIDAD Y LA CONSE- CUENCIA PRÁCTICA DE LA REDUCCIÓN DE LA MAYORI- DAD PENAL CON SUS RESPECTIVAS CRÍTICAS}

\subsection{De la negligencia del Estado en el mantenimiento y la adecuación de las casas de internación en los moldes del estatuto del Niño y del Adolescente}

Es importante subrayar que las casas de internaciones para los adolescentes, que debían tener el carácter educativo, padecen la misma falta de infraestructura del sistema penitenciario, configurando un verdadero complejo prisional, sólo que destinados a adolescentes, donde la integridad física y

38 «No plano do direito penal, fala-se da função ou efeito criminógeno da própria lei penal. Poder-se-ia No campo do direito penal, tem-se salientado que a legislaçáo serviria para satisfazer, de forma sublimada, a «necessidade de vingança» do povo, evitando-se, então, a justiça por linchamento. Analogamente, satisfaz-se por leis punitivas ou restritivas de direitos à necessidade de «bodes expiatórios», estigmatizando-se determinados membros da sociedade e descarregando outros de responsabilidade ou sentimento de culpa. Porém, nessa hipótese, em não havendo eficácia dos preceitos legais, estaremos num típico caso de legislação simbólica». (Neves, 2007, p. 50). 
mental de esas personas en formación se deja al margen, configurando en antros impregnados de abusos físicos, relaciones sexuales forzadas y por la perversión de las drogas. ${ }^{39}$

\subsection{Un serio problema práctico: vaga y estructura en los presidios brasileños}

No se puede olvidar el problema de faltas de vacantes en el sistema penitenciario brasileño.

En Brasil, según datos del Ministerio de Justicia, hay una población carcelaria de 607731 mil presos. Sin embargo, se cuenta con apenas 376669 mil plazas, totalizando un déficit de 231062 mil plazas (Brasil). Se suman a ese caos los mandatos de prisión en abierto, que, según los datos del Banco Nacional de Mandados de Prisión, son 486258 mil no cumplidos. ${ }^{40}$ De tal suerte, se tiene la necesidad, hoy, de al menos 717.320 nuevas plazas en el sistema penitenciario.

Tabla 1. Población carcelaria/vacantes en el sistema penitenciario/déficit, 2014 (Brasil)

\begin{tabular}{|c|c|c|}
\hline Populación carcelaria & Vacantes & Déficit inmediato \\
\hline $607731 \mathrm{mil}$ & $376669 \mathrm{mil}$ & $231062 \mathrm{mil}$ \\
\hline \multicolumn{2}{|c|}{ Mandatos de prisión o en libertad } & Déficit \\
\hline \multicolumn{2}{|c|}{$486258 \mathrm{mil}$} & $717320 \mathrm{mil}$ \\
\hline
\end{tabular}

Fuente: Elaboración propia

Esto es un dato expresivo, el cual no se puede ignorar o hacer poco caso. En estos términos, con la reducción de la edad penal para 16 años, donde estará la vacante, en el sistema penitenciario para el menor infractor?

No se tiene vagas y ni estructura en las casas de detención para menores, en los moldes del Estatuto del niño y del adolescente, el cual necesita una

39 É claro que se faz a ressalva de alguma intuição de internação espalhada pelos rincôes do Brasil que porventura seja um caso de sucesso, conseguindo perfilhar os ditames normativos do Estatuto da Criança e do Adolescente, onde este é modelo de excelência de uma construção legislativa do qual o Brasil padece de escassez.

40 Disponible en: http://www.cnj.jus.br/bnmp/\#/relatorio. 
protección especial e integral, quizá en el sistema penitenciario. Se dice aún más: es cierto que no será por la publicación de una ley, vehiculadora de un «deber-ser», que en "pase de magia» ese problema será resuelto.

Se destaca que en la presente investigación no se consiguió levantar datos para determinar si la reducción de la mayoría de edad penal afectaría al sistema penitenciario brasileńo, teniendo en vista la ausencia de un centro de informaciones nacional sobre la práctica de actos infractores y el número de menores en salud de la sanción de internación.

Se destaca, por ejemplo, el Estado de Rio Grande do Norte, donde los datos estadísticos entre la Fundación Estadual del Niño y del Adolescente (FUNDAC) y el Tribunal de Justicia de Rio Grande do Norte son completamente divergentes, lo que imposibilita un real diagnóstico del escenario de los actos infractores perpetrados en el respectivo Estado. ${ }^{41}$

En ácida crítica, se pronuncia el profesor Ney Moura Teles:

Soa, por fim, como piada a proposta, uma vez que o Estado brasileiro não tem sido capaz de construir estabelecimentos prisionais para atender às necessidades atuais de vagas para os condenados a penas privativas de liberdade. Se a capacidade penal alcançar os adolescentes, como se propóe, então a falência do sistema penitenciário será ainda mais estrondosa. (2006, p. 299).

\section{DE LAS CONSIDERACIONES FINALES}

En los términos presentados, se vislumbra que el contenido normativo del artículo 228 de la Constitución Federal constituye un derecho individual fundamental de que nińos y adolescentes sean procesados y castigados por una legislación especial distinta de la reservada a los mayores de 18 años constituyéndose en una verdadera cláusula pétrea inspirada en la doctrina de la protección integral del menor y en la normatividad del principio de intervención mínima del Derecho penal.

De tal suerte, otro entendimiento no podría ser más allá de aquel que considera flagrantemente inconstitucional la Propuesta de Enmienda a la Constitución N. ${ }^{\circ}$ 171/92, siendo una legislación meramente simbólica, embebida en carácter ideológico y como parca justificaba del Estado, en

41 Disponible en: http://tribunadonorte.com.br/noticia/faltam-estata-sticas-para-nortear-debate-sobre-maioridade/316996. Consulta en línea: 11 de dezembro de 2015. 
relación a la sociedad, en lo que tante sus acciones en la lucha contra la criminalidad.

Se está vendiendo una ilusión sobre la problemática. En caso de aprobación de la respectiva PEC, se tendrá un aumento de la violencia, marginará aún más a los jóvenes en formación y, finalmente, y se contribuye al agravamiento del caos del sistema penitenciario brasileño.

El Derecho Penal no es y nunca fue la solución para las olas de violencia y de crímenes. En el caso de que no se trabaje en políticas capaces de elevar la enseńanza de calidad, promover la disminución de las desigualdades sociales, y en lo referente a los menores, efectivizar sus derechos en los exactos términos del estatuto del niño y del adolescente, el Derecho Penal producido en Brasil continuará siendo un derecho penal simbólico.

Recordar que aquel menor infractor, marginado por la sociedad y el Estado, provenía muchas veces de una familia desestructurada, en la cual sólo conoció la violencia, distante de lo que todo el mundo quiere, amor y cariño. El Derecho Penal no proporciona ninguno de los dos.

\section{BIBLIOGRAFÍA}

Alexy, R. (2008). Teoria dos direitos fundamentais. Tradução Virgílio Afonso da Silva. São Paulo: Malheiros.

Bitencourt, C. (2010). Tratado de direito penal - parte geral. V. I. $15^{\circ}$ ed. São Paulo: Saraiva, 2010.

Brasil. Constituição da República Federativa do Brasil: atualizada até a Emenda Constitucional $N .^{\circ}$ 99. Brasília, DF, 5 de outubro de 1988. Disponible en: https://bit.ly/35OPqUd

Brasil. Decreto-lei n. ${ }^{\circ} 2.848$, de 7 de dezembro de 1940. Código Penal. Diário Oficial da Uniāo. Brasília, DF, 31 de dezembro de 1940. Disponible en: https://bit.ly/3fDJO3u

Brasil. Lei N. ${ }^{\circ} 8.069$, de 13 de julho de 1990. Dispóe sobre o Estatuto da Criança e do Adolescente e dá outras providências. Diário Oficial da União. Brasília, DF, 16 de julho de 1990. Disponible en: http://www.planalto.gov.br/ccivil_03/LEIS/L8069.htm.

Brasil. Decreto n. 99.710 , de 21 de novembro de 1990. Promulga a Convenção sobre os Direitos da Criança. Diário Oficial da União. Brasília, DF, 22 de novembro de 1990. Disponible en: https://bit.ly/3cNVGhF 
Brasil. Levantamento nacional de informaçóes penitenciárias - INFOPEN - junho de 2014. Ministério da Justiça. Brasília: 2014. Disponible en: https://bit. ly/2SWoZ9G

Campilongo, C. (2011). Direito e diferenciação social. São Paulo: Saraiva.

Canotilho, J., Leoncy, L., Mendes, G., Sarlet, I. \& Streck, L. (coords). (2013). Comentários à Constituição do Brasil. São Paulo: Saraiva.

Dias, J. (2007). Direito Penal - Parte Geral. Tomo I. São Paulo: RT.

Dotti, R. (2010). Curso de Direito Penal-parte geral. 3. ${ }^{\text {a }}$ ed. São Paulo: Revista dos Tribunais.

Fernandes, V. \& Fernandes, N. (2012). Criminologia integrada. 4.a ed. São Paulo: Revista dos Tribunais.

França, G. (2008). Medicina Legal. 8. ${ }^{a}$ ed. Rio de Janeiro: Guanabara Koogan.

Franco, A. \& Stoco, R. (coords). (2007). Código penal e sua interpretação. 8. ${ }^{\mathrm{a}} \mathrm{ed}$. São Paulo: RT.

Führer, M. R. y Führer, M. C. (2010). Código Penal Comentado. 3. ${ }^{a}$ ed. Malheiros: São Paulo.

Greco, R. (2011). Curso de direito penal-parte geral. V. I. 13. ${ }^{\text {a }}$ ed. Rio de Janeiro: Impetus,

Lenza, P. (2014). Direito Constitucional esquematizado. 18. a ed. São Paulo: Saraiva.

Mazzuoli, V. (2007). Curso de Direito Internacional Público. 2. a ed. São Paulo: RT.

Mendes, G. \& Branco, P. Curso de Direito Constitucional. 7. a ed. São Paulo: Saraiva.

Mendes, G., Coelho, I. \& Branco, P. (2009). Curso de Direito Constitucional. 4. ${ }^{2}$ ed. São Paulo: Saraiva.

Neves, M. (2007). A constitucionalização simbólica. São Paulo: Martins Fontes.

Nucci, G. (2009). Manual de direito penal. 5. a ed. São Paulo: Revista dos Tribunais.

Piovesan, F. (2015). Direitos humanos e o Direito Constitucional Internacional. 15. ${ }^{2}$ ed. São Paulo: Saraiva.

Reale, M. (2004). Instituiçóes de Direito Penal-Parte geral. V. I. 2. a ed. Rio de Janeiro: Forense.

Sposato, K. (2011). A constitucionalização do direito da criança no Brasil como barreira à redução da idade penal. Piovesan, F. \& Garcia, M. (Orgs). Doutrinas essências: direitos humanos. V. IV. São Paulo: RT.

Teles, N. (2006). Direito Penal-parte geral. 2. ${ }^{a}$ ed. São Paulo: Atlas. 